\title{
Effect of Different Activated Carbon as Carrier on the Photocatalytic Activity of Ag-N-ZnO Photocatalyst for Methyl Orange Degradation under Visible Light Irradiation
}

\author{
Xiaoqing Chen, Zhansheng Wu * (1), Zhenzhen Gao and Bang-Ce Ye \\ School of Chemistry and Chemical Engineering/The Key Laboratory for Green Processing of Chemical \\ Engineering of Xinjiang Bingtuan, Shihezi University, Shihezi 832003, China; chenxq0405@126.com (X.C.); \\ zhenzhengao1210@163.com (Z.G.); bcye@ecust.edu.cn (B.-C.Y.) \\ * Correspondence: wuzhans@126.com; Tel.: +86-993-205-5015; Fax: +86-993-205-7270
}

Received: 1 August 2017; Accepted: 1 September 2017; Published: 5 September 2017

\begin{abstract}
In order to enhance the photodegradation of methyl orange (MO) by $\mathrm{ZnO}$ under visible light irradiation, $\mathrm{ZnO}$ nanoparticles co-doped with $\mathrm{Ag}$ and $\mathrm{N}$ and supported on activated carbon (AC) with different properties were synthesized through the sol-gel method. The prepared photocatalysts were characterized in terms of the structure and properties through X-ray diffraction, $\mathrm{N}_{2}$ adsorption-desorption, ultraviolet-visible (UV-vis), diffuse reflectance spectroscopy, $\mathrm{X}$-ray photoelectron spectroscopy, photoluminescence, and electron spin resonance. The photocatalytic activities of these photocatalysts followed the order: Ag-N-ZnO/ACs $>\mathrm{Ag}-\mathrm{N}-\mathrm{ZnO}>\mathrm{N}$, or Ag single-doped $\mathrm{ZnO}>$ commercial $\mathrm{ZnO}$. This result was attributed to the small particle size, large surface area, narrow band gap, and high charge separation of $\mathrm{Ag}-\mathrm{N}-\mathrm{ZnO} / \mathrm{ACs}$. The $\mathrm{Ag}-\mathrm{N}-\mathrm{ZnO} /$ coconut husk activated carbon (Ag-N-ZnO/CHAC) exhibited the highest degradation efficiency of $98.82 \%$ for $\mathrm{MO}$ under visible light irradiation. This outcome was due to the abundant pore structure of $\mathrm{Ag}-\mathrm{N}-\mathrm{ZnO} / \mathrm{CHAC}$, resulting in stronger adsorption than that of other Ag-N-ZnO/ACs. Moreover, the degradation of $\mathrm{MO}$ on photocatalysis followed first order kinetics. The reactive species $\cdot \mathrm{OH}$ and $\cdot \mathrm{O}_{2}{ }^{-}$ played more important roles in the photocatalytic degradation of MO over composite photocatalyst. $\mathrm{Ag}-\mathrm{N}-\mathrm{ZnO} / \mathrm{CHAC}$ photocatalyst exhibited higher photocatalytic activity than unsupported Ag-N-ZnO after five recycling runs.
\end{abstract}

Keywords: photocatalytic degradation; zinc oxide; activated carbon; visible light; methyl orange

\section{Introduction}

With the rapid development of global industry, more and more environmental problems-especially water pollution-are caused by organic pollutants. Numerous kinds of synthetic dyes pollutants which are widely applied in textile, food, and leather industries, have been discharged into the natural environment. And these pollutants are highly hazardous to the health of human beings [1]. Methyl orange (MO) is the most representative of all anionic azo dyes, which is not decomposed under ambient conditions and is usually resistant to classical biological treatment. Conventional physicochemical techniques, such as adsorption, coagulation, and reverse osmosis, are the most frequently developed to remove MO from aqueous solutions. However, these methods can merely accumulate $\mathrm{MO}$ and cannot transform the dye into harmless compounds [2-6]. Hence, the development of an efficient treatment method for MO is a scientific problem of considerable interest. Recently, numerous researchers have focused on photocatalytic degradation to handle dyes because this approach can completely mineralize dyes in wastewater.

Zinc oxide $(\mathrm{ZnO})$ is one of the most popular photocatalysts due to its low toxicity, chemical stability, and superior photocatalytic properties [7-9]. ZnO presents a wide band gap of $3.37 \mathrm{eV}$, 
and can only be excited under UV light irradiation. However, sunlight consists of approximately $5 \%$ UV, 43\% visible and 52\% infrared [10] light, therefore the wide band gap of ZnO limits its photoactivity under visible light, which limits its applications that use sunlight as the energy source. Another drawback of $\mathrm{ZnO}$ is the rapid recombination rate of the photogenerated electron-hole pair, which limits the photodegradation reaction under normal conditions [11]. To overcome these drawbacks, numerous attempts have been made to prepare more efficient photocatalysts based on $\mathrm{ZnO}$ nanomaterials. One of the effective approaches to solve these shortcomings is to modify $\mathrm{ZnO}$ using metal and nonmetal dopants [12-14]. Numerous investigations on metal and nonmetal elements, such as $\mathrm{Ag}, \mathrm{Fe}, \mathrm{N}$, and $\mathrm{S}$, doped into $\mathrm{ZnO}$ have been conducted to enhance photocatalytic activity. Among these doped $\mathrm{ZnO}$ elements, $\mathrm{ZnO}$ single-doped with $\mathrm{N}$ can exhibit strong absorption in various reactions under visible light [15] and single Ag-doped $\mathrm{ZnO}$ can inhibit the recombination of photogenerated electrons and holes [12]. Therefore, it is worthwhile to investigate the effect of Ag and $\mathrm{N}$ co-doped-ZnO on the visible light response and inhibition of the recombination of photogenerated electrons and holes, which has considerable practical application value.

Moreover, it is difficult to recover the pure $\mathrm{ZnO}$ powder from the treated effluent, which limits the practical application of $\mathrm{ZnO}$ photocatalyst in industry. Finding effective approaches in order to solve the problem is very important. Until now, photocatalysts have been immobilized using various supports, which are generally porous materials. Many different porous materials have been investigated, such as activated carbon, zeolites, and glass [16-18]. Among these porous materials, AC is widely used as a photocatalyst carrier because of large specific surface area and rich functional groups [19-21]. Meanwhile, in the process of dye wastewater treatment, AC supported $\mathrm{ZnO}$ could be separated and reused easily from suspension, thus the lifetime of photocatalyst could be lengthened [22]. Furthermore, AC supported $\mathrm{ZnO}$ adsorbs a large number of pollutants and toxic intermediates formed after the initial degradation. Then, the photocatalytic degradation efficiency is improved [13]. However, the preparation of AC loaded, Ag and N co-doped-ZnO photocatalyst for the degradation of $\mathrm{MO}$ has yet to be reported. In addition, it is worth thoroughly researching the influence of ACs with different performance for supporting Ag and N co-doped ZnO photocatalyst on the photocatalytic degradation efficiency of $\mathrm{MO}$.

The present work focuses on the synthesis of different AC loaded Ag-N-ZnO for MO removal. The crystal structure, morphology observation, and chemical properties of the photocatalysts were characterized by various techniques. The adsorption performance, the photocatalytic properties and stability of the photocatalysts were investigated using the removal rate of $\mathrm{MO}$. The influences of different ACs prepared with coconut husk $(\mathrm{CH})$, coal $(\mathrm{C})$ and almond (A) (i.e., CHAC, coal activated carbon (CAC), and almond activated carbon (AAC)) to load Ag, $\mathrm{N}$ co-doped $\mathrm{ZnO}$ photocatalyst on photocatalytic degradation efficiency were also studied. The obtained results could be significant for the application of $\mathrm{ZnO}$ as a photocatalyst to remove $\mathrm{MO}$.

\section{Material and Methods}

\subsection{Materials}

Zinc acetate was purchased from Tianjin Fuchen Chemical Reagent Co., Ltd. (Tianjin, China). Oxalic acid and urea were supplied by Tianjin Shengao Chemical Industry Limited Company (Tianjin, China). EtOH (anhydrous alcohol) was provided by Tianjin Fuyu Fine Chemical Co., Ltd. (Tianjin, China). $\mathrm{MO}$ and $\mathrm{AgNO}_{3}$ were obtained from Tianjin Yongsheng Fine Chemical Co., Ltd. (Tianjin, China). All reagents were of analytical grade and used without further purification.

\subsection{Preparation Ag-N-ZnO/ACs}

The photocatalysts were prepared based on previous studies [23]. In a typical synthesis, zinc acetate (2.196 g) was dissolved in absolute ethanol (EtOH) $(60 \mathrm{~mL})$ under stirring in water bath of $60{ }^{\circ} \mathrm{C}$ for $30 \mathrm{~min}$ and then it was named solution A. Solution B was prepared by mixing $5.040 \mathrm{~g}$ of oxalic 
acid dehydrate in $80 \mathrm{~mL}$ of EtOH under stirring in water bath of $50{ }^{\circ} \mathrm{C}$ for $30 \mathrm{~min}$. Solution $\mathrm{B}$ was added dropwise to the warm solution $\mathrm{A}$ and the resulting solution was continuously stirred at room temperature for $1 \mathrm{~h}$ to get sol. The sol was aged in a sealed environment for $48 \mathrm{~h}$ until a homogenous gel was formed. Next, the product was dried in a vacuum oven at $80^{\circ} \mathrm{C}$ for $24 \mathrm{~h}$. Finally, $\mathrm{ZnO}$ was obtained by thermal treating at $400{ }^{\circ} \mathrm{C}$ for $2 \mathrm{~h}$. To prepare $\mathrm{Ag}-\mathrm{N}-\mathrm{ZnO}, 0.034 \mathrm{~g}$ of $\mathrm{AgNO}_{3}$ and $0.9 \mathrm{~g}$ of urea was dissolved in solution A. Then, $2.0 \mathrm{~g}$ CHAC was dispersed in $200 \mathrm{~mL}$ ethanol for $1 \mathrm{~h}$ under sonication and $0.2 \mathrm{~g} \mathrm{ZnO}$ was dispersed in $50 \mathrm{~mL}$ ethanol for $20 \mathrm{~min}$. Both solutions were intermixed and the mixture was subsequently sonicated for $1 \mathrm{~h}$ and then stirred for $15 \mathrm{~h}$ at $300 \mathrm{rpm}$. The resulted samples were separated via centrifugation and dried at $80^{\circ} \mathrm{C}$ and noted as Ag-N-ZnO/CHAC. Ag-N-ZnO/CAC and $\mathrm{Ag}-\mathrm{N}-\mathrm{ZnO} / \mathrm{AAC}$ were prepared by the same method.

\subsection{Characterization Methods}

The X-ray diffraction (XRD) patterns of all samples were analyzed using a Rigaku Giegerflex D/Max $\mathrm{B}$ diffractometer (Rigaku Corporation, Tokyo, Japan) with $\mathrm{Cu}-\mathrm{K} \alpha$ radiation. The scanning step and velocity used was $0.02^{\circ}$ and $0.01^{\circ}$ /minutes, respectively. The samples were scanned in the angle range of $10^{\circ}-80^{\circ}$. The pore volume, pore size distribution, and specific surface area of samples were characterized by $\mathrm{N}_{2}$ adsorption at $77 \mathrm{~K}$ using a surface area analyzer (Micromeritics, ASAP 2020, Norcross, GA, USA). UV-Visible absorbance spectra to determine the optical band gap of the photocatalysts were registered by a UV-Visible spectrophotometer (Hitachi UV-4100, Hitachi, Tokyo, Japan), in which $\mathrm{BaSO}_{4}$ was used as the reflectance standard. Surface composition and chemical states were conducted using X-ray photoelectron spectroscopy (XPS) (Thermo ESCALAB 250XI, Thermo Fisher Scientific, Waltham, MA, USA) equipped with an $\mathrm{Mg} \mathrm{K} \alpha$ X-ray source $(1253.6 \mathrm{eV})$ under a vacuum pressure $<10^{-6} \mathrm{~Pa}$. Photoluminescence (PL) spectra of the samples were measured by a fluorescence spectrophotometer (FLsp920, British Edinburgh, Edinburgh, UK) at room temperature using Xe lamp as an excitation light source.

Electron spin resonance (ESR) signal of the radicals spin trapped by 5,5-dimethyl-1-pyrroline- $N$-oxide (DMPO, supplied from Sigma Co., Ltd., Saint Louis, MO, USA) was recorded using JES FA200 spectrometer (JEOL Ltd., Tokyo, Japan ). In detail, the sample (5 mg) was dispersed in the solvent benzotrifluoride (BTF, $5 \mathrm{~mL}$ ). Then, $25 \mathrm{~mL}$ DMPO/toluene solution $(1: 10, v / v)$ was added and oscillated to achieve the well-blended suspension. The settings for the ESR spectrometer were as follows: center field $=3507 \mathrm{G}$, microwave frequency $=9.84 \mathrm{GHz}$ and power $=6.36 \mathrm{~mW}$.

\subsection{Adsorption Experiments}

To investigate the adsorption performance of the prepared photocatalyst, the experiment of adsorption of $\mathrm{MO}$ on photocatalyst was performed. $0.01 \mathrm{~g}$ of the photocatalyst was added into $50 \mathrm{~mL}$, $30.0 \mathrm{mg} / \mathrm{L}$ of $\mathrm{MO}$ solution and then stirred the solution at $25^{\circ} \mathrm{C}$ for $60 \mathrm{~min}$ in the dark. The suspension obtained was filtered, and the concentrations of MO were measured using a UV5100 spectrophotometer at $466 \mathrm{~nm}$. The amount of $\mathrm{MO}$ adsorbed $\left(q_{t}\right)$ on samples at the same time intervals was calculated as follows:

$$
q_{t}=\frac{\left(C_{0}-C_{t}\right) V}{m}
$$

where $C_{0}$ and $C_{t}(\mathrm{mg} / \mathrm{L})$ are the concentrations of $\mathrm{MO}$ at initial and the same time intervals, respectively. $V$ is the volume of the aqueous solution $(\mathrm{L})$, and $m(\mathrm{~g})$ is the weight of the added photocatalyst.

\subsection{Photocatalytic Activity for MO Degradation}

Photocatalytic experiments were performed to investigate the degradation of $\mathrm{MO}$ solution over photocatalyst by using a $500 \mathrm{~W}$ Xe lamp (power adjustment range: 100 1000 W; any irradiation below $420 \mathrm{~nm}$ was removed using a cut-off filter) as the visible light source. The power of Xe lamp was kept $500 \mathrm{~W}$ and an average irradiation intensity of $350 \mathrm{~W} / \mathrm{m}^{2}$ was maintained throughout the experiments. The distance between the reactor and lamp housing is $8.5 \mathrm{~cm}$. The temperature was controlled at about $25^{\circ} \mathrm{C}$ using cold trap and cooling water circulation pump during the photocatalytic reaction. 
$0.01 \mathrm{~g}$ of photocatalyst was added to $50 \mathrm{~mL}$ of MO solution $(30 \mathrm{mg} / \mathrm{L})$. The mixture was continuously magnetically stirred and kept in the dark for $60 \mathrm{~min}$ to allow adsorption-desorption equilibrium between $\mathrm{MO}$ and the photocatalyst. Successively, the suspension was exposed under visible light in order to degrade MO. After degradation experiment, each sample was immediately filtered to remove photocatalyst for analysis. The concentration of MO in clear liquid was measured. The degradation efficiency $(\eta)$ of $\mathrm{MO}$ can be calculated as follows:

$$
\eta=\frac{C_{0}-C_{t}}{C_{0}} \times 100 \%
$$

where $C_{0}$ and $C_{t}(\mathrm{mg} / \mathrm{L})$ are the concentrations of $\mathrm{MO}$ at the initial and different irradiation times, respectively.

\subsection{Radicals Scavenging Experiments}

To further study the photocatalytic mechanisms of photocatalyst, the radical scavenging experiments were carried out. The holes $\left(\mathrm{h}^{+}\right)$, hydroxyl radical $(\cdot \mathrm{OH})$, the electrons $\left(\mathrm{e}^{-}\right)$and superoxide radical $\left(\cdot \mathrm{O}_{2}{ }^{-}\right)$are trapped by adding ammonium oxalate $(\mathrm{AO})\left(\mathrm{h}^{+}\right.$scavenger $)$, tert-butanol $(t-\mathrm{BuOH})$ (.OH scavenger), $\mathrm{K}_{2} \mathrm{~S}_{2} \mathrm{O}_{8}\left(\mathrm{e}^{-}\right.$scavenger) and $p$-benzoquinone $(p-\mathrm{BQ})\left(\cdot \mathrm{O}_{2}{ }^{-}\right.$scavenger) into the reaction solution, respectively. Typically, $0.01 \mathrm{~g}$ of photocatalyst and $10 \mathrm{mM}$ of radical scavengers were placed into $50 \mathrm{~mL}$ of $30 \mathrm{mg} / \mathrm{L}$ dye solution, then, the suspension was irradiated under the same conditions of photocatalytic experiments. Finally, the degradation efficiency $(\eta)$ of dye can be calculated to determine the main role of active species.

\section{Results and Discussion}

\subsection{X-ray Diffraction}

The XRD patterns of all samples prepared are shown in Figure 1 . The peak at $2 \theta=31.81^{\circ}, 34.44^{\circ}$, $36.21^{\circ}, 47.60^{\circ}, 56.62^{\circ}, 63.01^{\circ}$, and $67.97^{\circ}$ correspond to the (100), (002), (101), (102), (110), (103), and (112) planes of hexagonal wurtzite structure of $\mathrm{ZnO}$. All pertinent diffraction data for $\mathrm{ZnO}$ matched well with the reported data (JCPDS 36-1451) [23]. Evidently, the Ag-N-ZnO and Ag-N-ZnO/ACs composites with different $A C$ s loading have the similar XRD patterns, which implied that the addition of $\mathrm{Ag}, \mathrm{N}$ and $\mathrm{AC}$ does not change the phase structure of $\mathrm{ZnO}$. However, no apparent characteristic diffraction peaks of Ag and $\mathrm{N}$ were observed in the XRD patterns of all samples prepared, which could be attributed to the low doping amount. Similarly, Bhirud et al. [15] have reported this phenomenon in their studies. Moreover, the characteristic diffraction peak of AC was not detected in the Ag- $\mathrm{N}-\mathrm{ZnO} / \mathrm{AC}$ composites, which is probably due to the relatively low diffraction intensity of $\mathrm{AC}$ [24]. Compared with Ag-N-ZnO, the peak intensity of $\mathrm{Ag}-\mathrm{N}-\mathrm{ZnO} / \mathrm{AC}$ reduced, which was attribute to the lower amount of crystalline material $(\mathrm{ZnO})$ in a matrix of amorphous matter $(\mathrm{AC})$.

The average crystallite sizes of photocatalysts obtained were calculated from the hexagonal wurtzite (101) peaks using the Debye-Scherrer formula, and the estimated lattice spacing are listed in Table 1. All Ag-N-ZnO/ACs presented smaller crystallite sizes than Ag-N-ZnO because AC acts as barrier to the inhibitive action of crystal growth [22]. The particle size of Ag-N-ZnO/AHAC was $12.1 \mathrm{~nm}$, which was the smallest among all samples. Smaller crystallite size could be conducive to enhancing the photocatalytic activity of photocatalyst. It is similar to the report of Wang et al. [10]. 


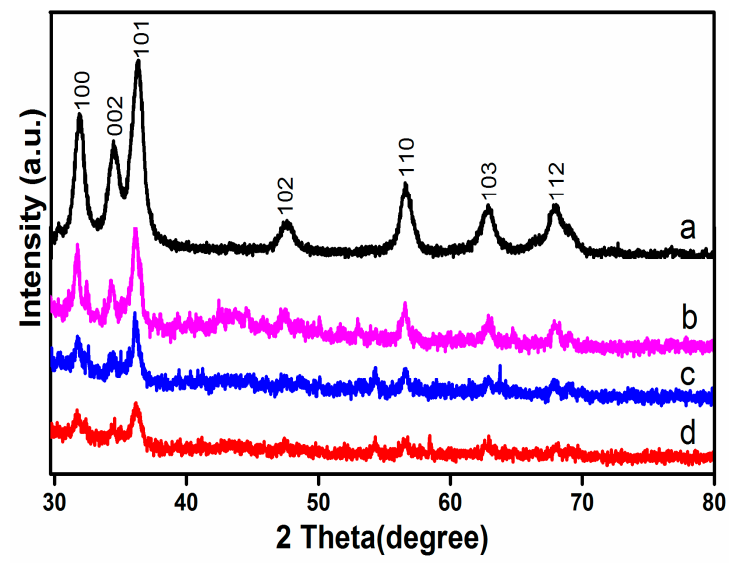

Figure 1. XRD patterns of $\mathrm{Ag}-\mathrm{N}-\mathrm{ZnO}$ (a), $\mathrm{Ag}-\mathrm{N}-\mathrm{ZnO} / \mathrm{CHAC}$ (b), $\mathrm{Ag}-\mathrm{N}-\mathrm{ZnO} / \mathrm{CAC}$ (c), and $\mathrm{Ag}-\mathrm{N}-\mathrm{ZnO} / \mathrm{AAC}(\mathbf{d})$.

Table 1. Characteristics of different photocatalysts.

\begin{tabular}{|c|c|c|c|c|c|c|}
\hline Samples & Crystallite Size $(\mathrm{nm})^{a}$ & $D(101)(n m)^{b}$ & $S_{\mathrm{BET}}\left(\mathrm{m}^{2} / \mathrm{g}\right)$ & $V_{\mathrm{t}}\left(\mathrm{cm}^{3} / \mathrm{g}\right)$ & Average Pore Size (nm) & Band Energy (eV) \\
\hline $\mathrm{Ag}-\mathrm{N}-\mathrm{ZnO}$ & 18 & 0.2477 & 40 & 0.2258 & 13.13 & 2.83 \\
\hline $\mathrm{Ag}-\mathrm{N}-\mathrm{ZnO} / \mathrm{CHAC}$ & 12 & 0.2480 & 472 & 0.4348 & 1.35 & 2.52 \\
\hline Ag-N-ZnO/CAC & 14 & 0.2482 & 252 & 0.2542 & 1.35 & 2.55 \\
\hline CHAC & - & - & 593 & 0.5037 & 1.35 & - \\
\hline CAC & - & - & 312 & 0.2769 & 1.35 & - \\
\hline $\mathrm{AAC}$ & - & - & 276 & 0.2545 & 1.35 & - \\
\hline
\end{tabular}

$S_{\mathrm{BET}}$, specific surface area obtained by BET equation; $V_{\mathrm{t}}$ total pore volume; Average pore size from pore size distribution determined by Barret Joyner Halenda $(\mathrm{BJH})$ method. ${ }^{a}$ Based on XRD analysis, using the Scherrer equation: crystalline size $=0.89 \lambda / \beta \cos \theta$, where $\lambda=0.154 \mathrm{~nm}, \beta$ is the full width at half maximum (FWHM), and $\theta$ is the diffraction angle. ${ }^{b}$ Based on XRD analysis using Bragg's law: lattice spacing $(D)=\lambda /(2 \times \sin \theta)$. Band energy retrieved from Kubelka-Munk elaboration by plotting $(a h v)^{1 / 2}$ versus energy of light $(h v)$.

\section{2. $\mathrm{N}_{2}$ Adsorption-Desorption}

$\mathrm{N}_{2}$ adsorption-desorption isotherms and Barret Joyner Halenda (BJH) desorption pore distribution of all samples prepared are shown in Figure 2. In reference to the international union of pure and applied chemistry (IUPAC) classification, the isotherms of Ag-N-ZnO and Ag-N-ZnO/ACs belong to type IV with type $\mathrm{H} 4$ hysteresis loops which indicates the existence of mesoporous structure (2-50 nm) The surface area and porous structure of Ag-N-ZnO, Ag-N-ZnO/CHAC, Ag-N-ZnO/CAC, and $\mathrm{Ag}-\mathrm{N}-\mathrm{ZnO} / \mathrm{AAC}$ were determined using nitrogen gas adsorption-desorption isotherms. Table 1 shows the parameters of their physical properties such as specific surface area, total pore volume and average pore diameter. As seen from Table 1, the average pore diameter of Ag-N-ZnO and Ag-N-ZnO/ACs were $13.13 \mathrm{~nm}$ and $1.35 \mathrm{~nm}$, which further confirmed the presence of mesopores of $\mathrm{Ag}-\mathrm{N}-\mathrm{ZnO}$ and micropores of $\mathrm{Ag}-\mathrm{N}-\mathrm{ZnO} / \mathrm{ACs}$, respectively. The pore channels allow light scattering in the interior and strengthen absorption light [10]. Compared with pure ACs, the specific surface area of all Ag-N-ZnO/ACs decreased, which was the result of two factors: (1) The crystal sizes were larger than the average pore size of AC. Thus, the large size particles mostly deposited on the surface of AC and led to decrease in the surface area of photocatalysts; and (2) the surface area of the composites decreased because $\mathrm{ZnO}$ has a markedly lower surface area with respect to ACs. Meanwhile, Ag-N-ZnO/ACs possess higher specific surface area than Ag-N-ZnO, and the BET surface area of $\mathrm{Ag}-\mathrm{N}-\mathrm{ZnO} / \mathrm{CHAC}$ is the largest. The larger surface area can help concentrate the $\mathrm{MO}$ molecules and the $\mathrm{MO}$ molecules approach to the photo-active sites [10,13]. 


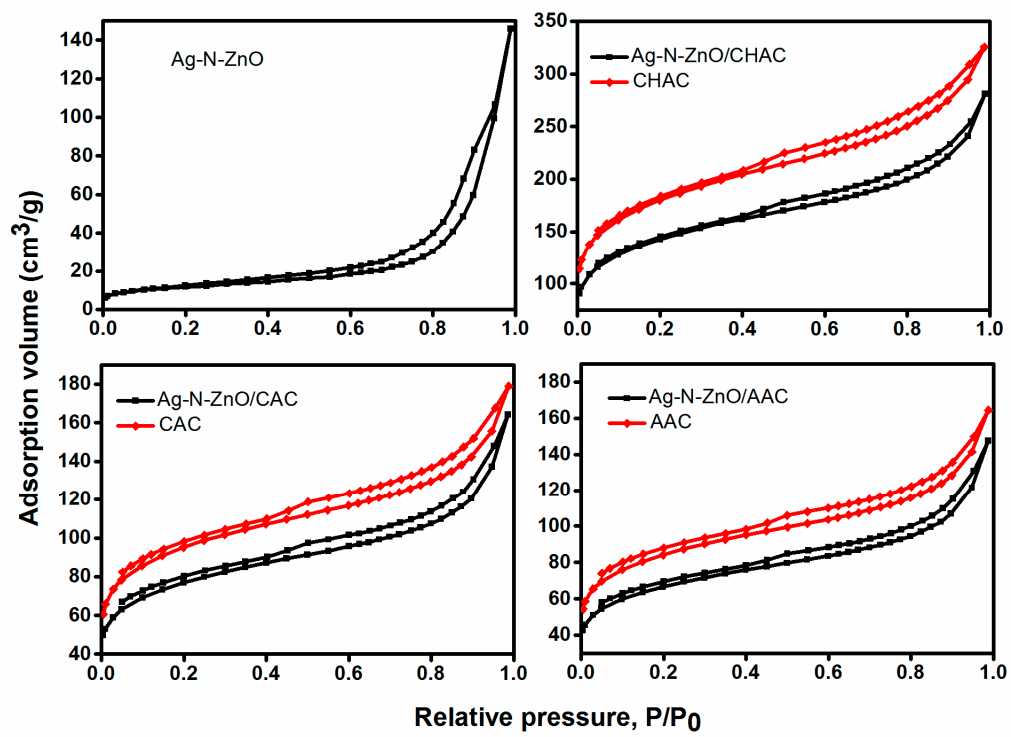

Figure 2. $\mathrm{N}_{2}$ adsorption/desorption isotherms curves of Ag-N-ZnO, Ag-N-ZnO/CHAC, Ag-N-ZnO/CAC and Ag-N-ZnO/AAC.

\subsection{UV-Vis Diffuse Absorption Spectra}

The photoabsorption behavior of the synthesized composite photocatalysts was investigated by using UV-vis diffuse absorption spectra. The results are given in Figure 3d. The band gap can be retrieved from Kubelka-Munk elaboration by plotting $(a h v)^{1 / 2}$ versus energy of light $(h v)$ as shown in Figure $3 a-d$, where $a$ is the absorption coefficient. The results are given in Table 1 . The band gaps of Ag-N-ZnO, Ag-N-ZnO/CHAC, Ag-N-ZnO/CAC and Ag-N-ZnO/AAC are 2.83, 2.52, 2.55, and $2.77 \mathrm{eV}$, respectively. This phenomenon could be attributed to the fact that Ag-N-ZnO/CHAC has an abundant pore structure, which allows light to scatter inside [10] and the absorption of CHAC at slightly higher wavelengths than that of pure $\mathrm{ZnO}$. The pure $\mathrm{ZnO}$ has strong absorption at a wavelength of $368 \mathrm{~nm}$, indicating the band gap of $3.37 \mathrm{eV}$ cited in the literature. Compared with the pure $\mathrm{ZnO}$, the band edge absorption of prepared composite photocatalysts were red shifted and exhibited extended absorption in the visible-light region ( $>400 \mathrm{~nm}$ ), which can be attributed to the charge transfer between the $\mathrm{Ag} 3 \mathrm{~d}$ or $\mathrm{N} 2 \mathrm{p}$ state as well as to the $\mathrm{ZnO}$ conduction or valance bands. The absorption edge is therefore extended to visible light, leading to the generation of electron-hole pairs, which enhances the photocatalytic properties of the composite photocatalyst [25]. The loading of the Ag-N-ZnO on AC results in a narrowing of the band-gap and the raising of the absorbance in the visible region, which is likely due to the formation of $\mathrm{Zn}-\mathrm{O}-\mathrm{C}$ just like carbon doping $\mathrm{ZnO}$ [26].
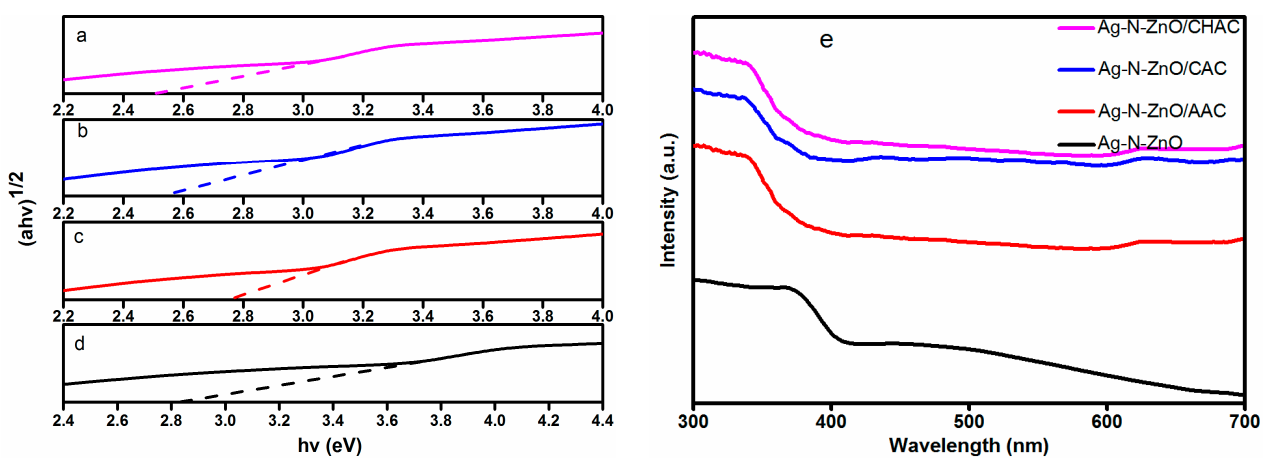

Figure 3. Direct band gap of (a) Ag-N-ZnO/CHAC, (b) Ag-N-ZnO/CAC, (c) Ag-N-ZnO/AAC (d) Ag-N-ZnO and (e) UV-vis diffuse absorption spectra of all photocatalysts. 


\subsection{Photoluminescence}

The photoluminescence (PL) spectra were carried out to estimate the charge recombination and migration efficiency, which is related closely to the photocatalytic properties of a photocatalyst [24]. The PL of all samples is shown in Figure 4. The PL spectra reveals similar curve shapes for all photocatalysts, which indicates that the loading AC affected the intensity of the PL spectra but did not result in a new PL phenomenon. The strong peak at around $410 \mathrm{~nm}$ was assigned to the near-band-edge emission of samples [27]. The band at around $435 \mathrm{~nm}$ correspond to blue emission, which may originate from some interface traps of radiative defects at the grain boundaries between silver and $\mathrm{ZnO}$ grains [28]. All composite materials display similar green light emission peaks centered at $560 \mathrm{~nm}$, which results from the recombination of a singly ionized oxygen vacancy with a photo generated hole [29]. The intensity of the PL spectra decreased in the order of Ag-N-ZnO > Ag-N-ZnO/AAC $>$ Ag-N-ZnO/CAC > Ag-N-ZnO/CHAC. From the XRD analysis, Ag-N-ZnO/CHAC shows the smallest particle size. The smaller particle could facilitate the rapid diffusion of photogenerated carriers to the semiconductor surface, resulting in decreasing the recombination rate of the carrier. A lower PL intensity means a lower electron-hole recombination rate and a higher separation efficiency, hence carriers have a longer lifetime [26]. Therefore, the efficient charge separation and inhibited electron-hole recombination could probably enhance the photocatalytic activity of photocatalysts.

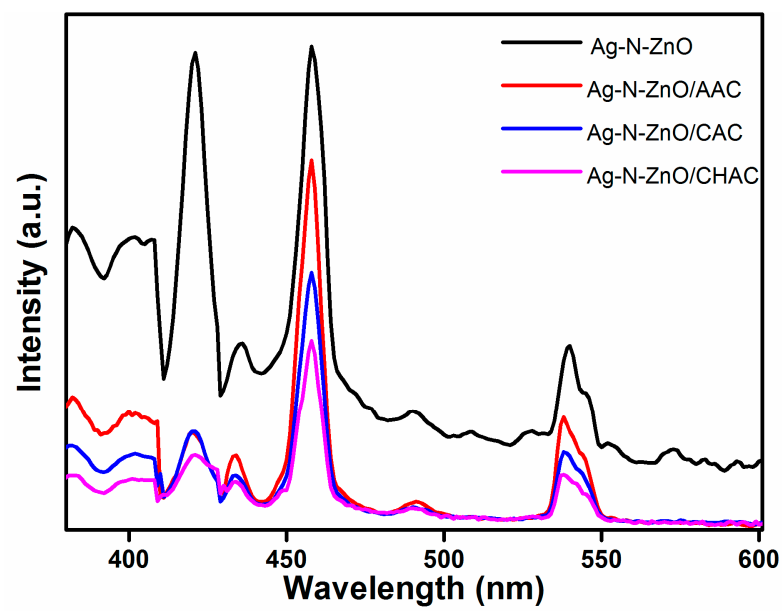

Figure 4. PL spectra of Ag-N-ZnO, Ag-N-ZnO/CHAC, Ag-N-ZnO/CAC and Ag-N-ZnO/AAC.

\subsection{X-ray Photoelectron Spectroscopy}

To investigate the surface chemical composite and chemical state of all samples, the X-ray Photoelectron Spectroscopy (XPS) of photocatalysts was studied (Figure 5). The binding energies were calibrated by using C 1s $(285.77 \mathrm{eV})$ as the reference. The typical XPS survey of all products shows that the composite photocatalyst only consists of $\mathrm{Zn}, \mathrm{O}, \mathrm{Ag}, \mathrm{N}$, and $\mathrm{C}$. No other elements were detected. The carbon peak of $\mathrm{Ag}-\mathrm{N}-\mathrm{ZnO}(\mathrm{C} 1 \mathrm{~s}=284.8 \mathrm{eV})$ was attributed to hydrocarbons from the XPS instrument. Nevertheless, the high-resolution XPS of Zn 2p, O 1s, and Ag 3d, C 1s shows that the binding energies of these electrons in the case of $\mathrm{Ag}-\mathrm{N}-\mathrm{ZnO}$ and $\mathrm{Ag}-\mathrm{N}-\mathrm{ZnO} / \mathrm{ACs}$ were slightly different, due to a strong interaction between the $\mathrm{Ag}, \mathrm{N}$, and $\mathrm{ZnO}$ nanoparticles and different $\mathrm{ACs}$ as carrier. In the $\mathrm{Zn} 2 \mathrm{p}$ XPS spectrum, the two specific peaks located at around $1023.3 \mathrm{eV}$ for $2 \mathrm{p}_{3 / 2}$ and $1046.4 \mathrm{eV}$ for $2 \mathrm{p}_{1 / 2}$, respectively. This outcome indicates that zinc element existed mainly as state of $\mathrm{Zn}^{2+}$ state in the all samples [30]. The O 1s XPS spectra of different photocatalysts were highly similar. The peaks at approximately $530.8 \mathrm{eV}$ of the samples were attributed to lattice oxygen present in $\mathrm{ZnO}$, whereas the main peak at around $532.0 \mathrm{eV}$ was assigned to hydroxyl groups absorbed onto the surface of the photocatalyst, which are related to the formation of hydroxyl radicals [31]. The presence of surface hydroxyl groups is in favor of the trapping of photogenerated electrons 
and holes to produce $\cdot \mathrm{OH}$, resulting in enhanced photocatalytic degradation. The core level $\mathrm{Ag} 3 \mathrm{~d}$ spectrum of Ag in composite photocatalyst consisted of two peaks at 367.5 and $374.5 \mathrm{eV}$ corresponding to $3 d_{5 / 2}$ and $3 d_{3 / 2}$ respectively, which can contribute to metallic silver $\left(\mathrm{Ag}^{0}\right)$ in the photocatalyst [32,33]. Effective nitrogen doping onto $\mathrm{ZnO}$ crystals can be confirmed by the obvious XPS signal of $\mathrm{N} 1 \mathrm{~s}$. The peaks at around $400.3 \mathrm{eV}$ may be attributed to $-\mathrm{Zn}-\mathrm{N}-\mathrm{O}-$ or $-\mathrm{O}-\mathrm{Zn}-\mathrm{N}-[30,34]$, indicating that some $\mathrm{O}$ atoms were substituted by nitrogen. These results strongly show the successful doping of nitrogen in $\mathrm{ZnO}$ crystals. Furthermore, the similar peaks indicated that the incorporation of Ag did not induce an obvious change in the chemical state of $\mathrm{N}$. The $\mathrm{C}$ 1s peaks of Ag-N-ZnO/CHAC, Ag-N-ZnO/CAC, and $\mathrm{Ag}-\mathrm{N}-\mathrm{ZnO} / \mathrm{AAC}$ located at around $285.2 \mathrm{eV}$ was signed to the $\mathrm{sp}^{2}$-hybridized carbon, which is attributed to the $\mathrm{AC}$ present in the synthesized composite material [10].
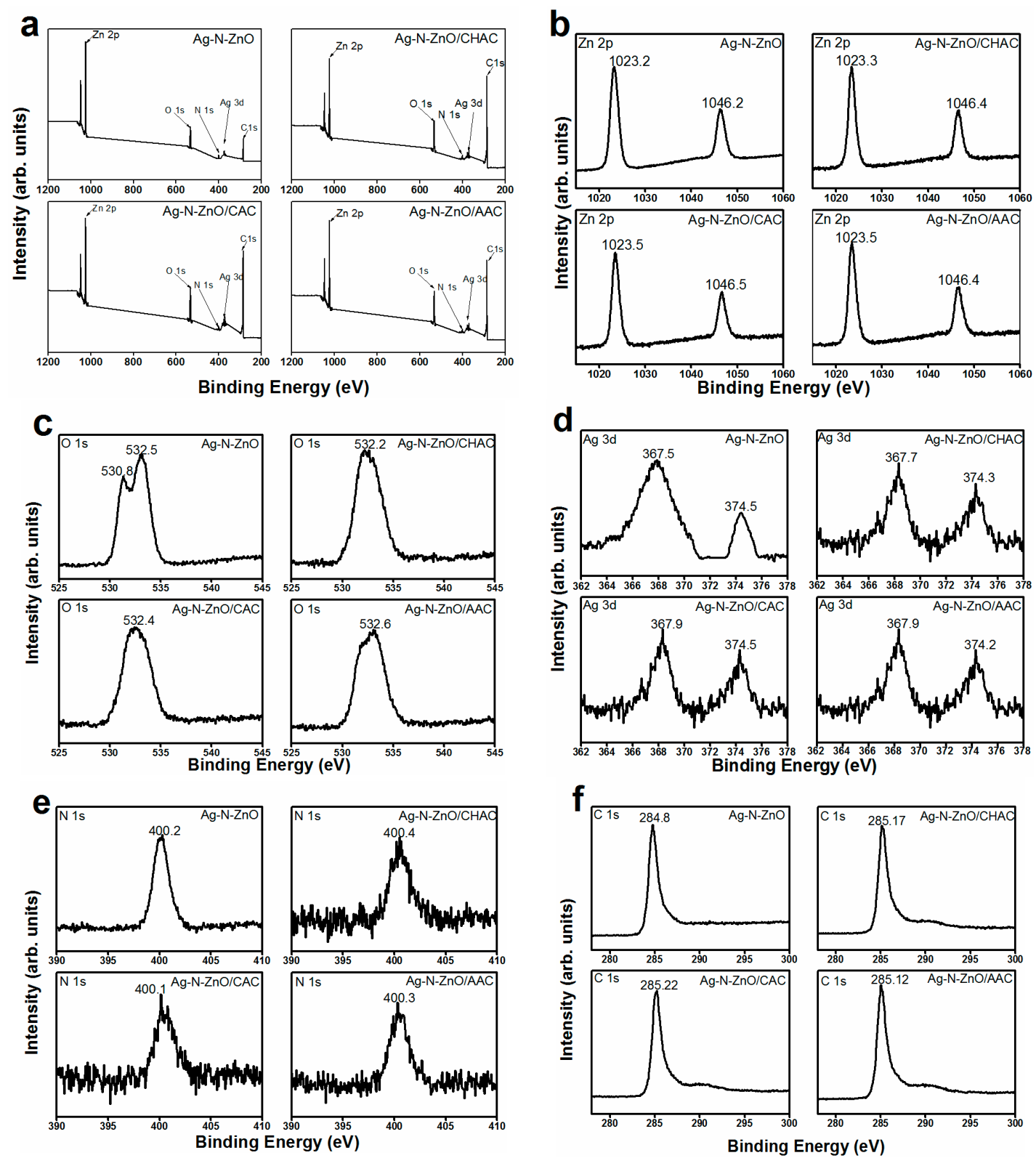

Figure 5. XPS spectra of survey spectra (a) Zn 2p (b), O 1s (c), $\mathrm{Ag} 3 \mathrm{~d}$ (d), $\mathrm{N}$ 1s (e) and $\mathrm{C} 1 \mathrm{~s}$ (f) levels of Ag-N-ZnO, Ag-N-ZnO/CHAC, Ag-N-ZnO/CAC and Ag-N-ZnO/AAC. 


\subsection{Adsorption Studies}

The adsorption kinetic curves of four composite photocatalysts were researched (Figure 6). It can be found that the four photocatalysts have similar adsorption behaviors. The adsorption process undergoes two steps: $\mathrm{MO}$ is rapidly adsorbed onto the photocatalyst surface within the first $10 \mathrm{~min}$ period. At the second step, the adsorption rate becomes slower until the adsorption equilibrium is reached because the number of available active sites gradually decreased. The adsorption process can almost reach equilibrium in about $60 \mathrm{~min}$. Among these photocatalysts, Ag-N-ZnO/CHAC composite photocatalyst exhibits the highest amounts of adsorption due to its large specific surface area [10].

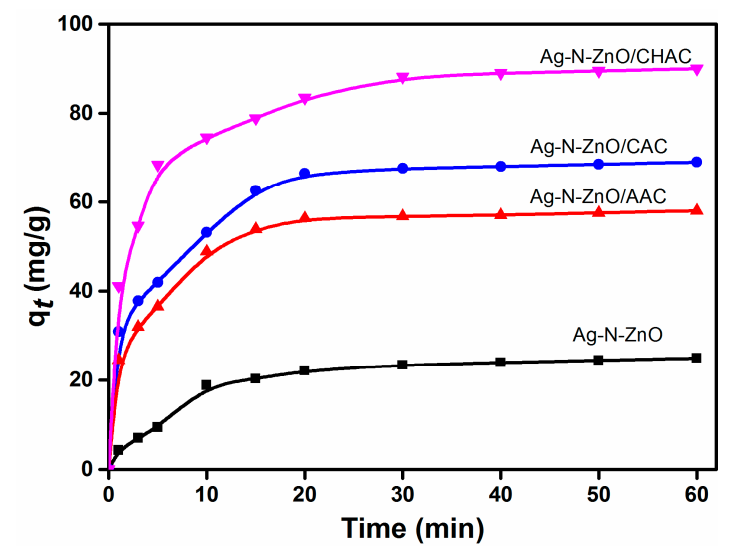

Figure 6. Adsorption kinetics of MO on the four composite photocatalysts.

Additionally, pseudo-first-order and pseudo-second-order models were introduced to study the adsorption kinetics of MO onto photocatalysts, whereas the intra-particle diffusion model was employed to further analyze the adsorption kinetic results and to verify whether the intra-particle diffusion was the only rate-determining step.

Pseudo-first-order model:

$$
q_{t}=q_{e}\left(1-e^{-k_{1} t}\right)
$$

Pseudo-second-order model:

$$
q_{t}=\frac{k_{2} q_{e}^{2} t}{1+k_{2} q_{e} t}
$$

Intra-particle diffusion model:

$$
q_{t}=k_{i d} t^{1 / 2}+C
$$

where $q_{e}(\mathrm{mg} / \mathrm{g})$ and $q_{t}(\mathrm{mg} / \mathrm{g})$ are the amounts of $\mathrm{MO}$ adsorbed at equilibrium and at time $t$ (min), respectively; $k_{1}\left(\mathrm{~min}^{-1}\right), k_{2}\left(\mathrm{~g} \cdot \mathrm{mg}^{-1} \cdot \mathrm{min}^{-1}\right)$ and $k_{i d}\left(\mathrm{mg} \cdot \mathrm{g}^{-1} \cdot \mathrm{min}^{-1 / 2}\right)$ are the rate constants of the pseudo-first-order, pseudo-second-order and intra-particle diffusion models of the adsorption process, respectively. $C$ is the intercept of the line, which is proportional to the boundary layer thickness.

Table 2 shows the parameters of the three kinetic models. The adsorption kinetics of MO onto composite photocatalysts can be better described using the pseudo-second-order model than the pseudo-first-order model. This phenomenon was due to the higher correlation coefficient values. Furthermore, the obtained theoretical values $\left(q_{e, c a l}\right)$ calculated from the pseudo-second-order model matched well with the experimental data $\left(q_{e, \text { exp }}\right)$. In addition, based on intra-particle diffusion model, the adsorption process consists of two steps. The first stage was related to the boundary layer diffusion of $\mathrm{MO}$ from the bulk solution to the external surface of the photocatalyst. The second stage was corresponded to the gradual diffusion of Mo through the boundary layer into the internal pores of photocatalyst until the adsorption equilibrium was reached. Similarly, Hou et al. have reported this phenomenon in their studies [35]. The lines did not pass through the origin, indicating that the intra-particle diffusion is not the exclusive rate-determining step [36]. 
Table 2. Kinetic parameters of MO adsorption onto the four composite photocatalysts.

\begin{tabular}{|c|c|c|c|c|c|c|c|c|c|c|c|c|c|}
\hline \multirow[b]{2}{*}{ Samples } & \multirow[b]{2}{*}{$q_{e, \exp }(\mathrm{mg} / \mathrm{g})$} & \multicolumn{3}{|c|}{ Pseudo-First-Order } & \multicolumn{3}{|c|}{ Pseudo-Second-Order } & \multicolumn{6}{|c|}{ Intra-Particle Diffusion Model } \\
\hline & & $q_{e, \mathrm{cal}}(\mathrm{mg} / \mathrm{g})$ & $k_{1}\left(\min ^{-1}\right)$ & $R^{2}$ & $q_{e, \mathrm{cal}}(\mathrm{mg} / \mathrm{g})$ & $k_{2}\left(\mathrm{~g} \mathrm{mg}^{-1} \cdot \min ^{-1}\right)$ & $R^{2}$ & $k_{i, 1}\left(\mathrm{mg} \mathrm{g}^{-1} \cdot \min ^{-1 / 2}\right)$ & $C_{1}(\mathrm{mg} / \mathrm{g})$ & $R^{2}$ & $k_{\mathrm{i}, 2}\left(\mathrm{mg} \mathrm{g}^{-1} \cdot \min ^{-1 / 2}\right)$ & $C_{2}(\mathrm{mg} / \mathrm{g})$ & $R^{2}$ \\
\hline Ag-N-ZnO & $25.14 \pm 0.02$ & $28.31 \pm 0.03$ & 0.1200 & 0.9827 & $24.53 \pm 0.05$ & 0.0054 & 0.9887 & 4.1580 & 0.0140 & 0.9978 & 1.2973 & 15.5364 & 0.9086 \\
\hline Ag-N-ZnO/CHAC & $90.42 \pm 0.04$ & $84.70 \pm 0.02$ & 0.3964 & 0.9413 & $90.71 \pm 0.02$ & 0.0073 & 0.9862 & 29.9700 & 3.8097 & 0.9566 & 3.3120 & 66.7464 & 0.8387 \\
\hline Ag-N-ZnO/CAC & $69.17 \pm 0.02$ & $66.10 \pm 0.04$ & 0.3664 & 0.9117 & $71.24 \pm 0.02$ & 0.0068 & 0.9602 & 18.6600 & 4.5380 & 0.8610 & 2.7166 & 50.2340 & 0.5983 \\
\hline Ag-N-ZnO/AAC & $58.28 \pm 0.04$ & $56.05 \pm 0.04$ & 0.2734 & 0.9447 & $60.39 \pm 0.04$ & 0.0070 & 0.9764 & 16.2880 & 3.0551 & 0.9140 & 1.5769 & 46.8706 & 0.6427 \\
\hline
\end{tabular}


Considering the influence of adsorption on photocatalysis, we put the catalysts into the MO solution in darkness before the photocatalytic runs to allow the adsorption of MO on the catalysts at equilibrium conditions. According to adsorption experiments, the adsorption process can almost reach equilibrium in about $60 \mathrm{~min}$, hence the mixture was kept in the dark for $60 \mathrm{~min}$.

\subsection{Photocatalytic Activity}

The photocatalytic performance of the different prepared photocatalysts was estimated by the degradation of MO under visible light irradiation after dark adsorption for $60 \mathrm{~min}$ (Figure 7a). A blank experiment was carried out under visible light irradiation for $120 \mathrm{~min}$ in the absence of photocatalysts, which indicated that the direct photolysis of MO could be negligible under visible light irradiation. The commercial $\mathrm{ZnO}$ exhibits virtually no activity under visible light irradiation. Compared with commercial $\mathrm{ZnO}$, the photocatalytic activity of $\mathrm{Ag}-\mathrm{ZnO}$ and $\mathrm{N}-\mathrm{ZnO}$ were enhanced. This phenomenon is due to the fact that $\mathrm{Ag}$ can act as an electron scavenger to trap the photogenerated electrons, thereby decreasing the recombination rate of electron-hole pairs [24]. Moreover, $\mathrm{N}$ doping can provide an impurity energy level above the valence band of $\mathrm{ZnO}$, thereby responding to the visible light and reducing the band gap [37]. The photocatalytic activity of $\mathrm{Ag}-\mathrm{N}-\mathrm{ZnO}$ is higher than single-doped $\mathrm{ZnO}$, which is attributed to intense visible light absorbance and a lower recombination rate of electrons and holes [38]. The Ag-N-ZnO loaded on AC exhibited a better photocatalytic degradation efficiency compared with pure Ag-N-ZnO. This result is reasonable on the basis of the two following factors: (1) The smaller particle size has more active sites at a constant amount of photocatalyst, which leads to an increase in the adsorption of $\mathrm{O}_{2}$ and $-\mathrm{OH}$, hence the generation of radicals is increased [23] and (2) AC may contribute to $\mathrm{MO}$ molecules gathered around $\mathrm{Ag}-\mathrm{N}-\mathrm{ZnO}$ particles in low concentration solution of $\mathrm{MO}$ [10]. These factors resulted in high photocatalytic activity. Among the all composite photocatalysts, the $\mathrm{Ag}-\mathrm{N}-\mathrm{ZnO} / \mathrm{CHAC}$ exhibits the highest photocatalytic activity and the degradation efficiency of $\mathrm{MO}$ reached $98.82 \%$ within 120 min under visible light radiation. Moreover, when the adsorption of the photocatalyst was eliminated, the degradation efficiency of MO can still reach 97.23\% within 120 min under visible light radiation (Figure $7 \mathrm{~b}$ ). This is due to three reasons: (1) The particle size of Ag-N-ZnO/CHAC is the smallest, which is in favor of adsorption of $\mathrm{O}_{2}$ and $-\mathrm{OH}$ to generate $\cdot \mathrm{OH}$ and $\cdot \mathrm{O}_{2}{ }^{-}$[23]; (2) The surface area of $\mathrm{Ag}-\mathrm{N}-\mathrm{ZnO} / \mathrm{CHAC}$ is the largest, which may contribute to more $\mathrm{MO}$ molecules gathering around $\mathrm{Ag}-\mathrm{N}-\mathrm{ZnO}$ [10]; and (3) The intensity of the PL of $\mathrm{Ag}-\mathrm{N}-\mathrm{ZnO} / \mathrm{CHAC}$ is the weakest, which indicates a decrease in the recombination rate of electrons and holes, thus increasing the life of electrons and holes [26]. These factors resulted in a highest photocatalytic activity of $\mathrm{Ag}-\mathrm{N}-\mathrm{ZnO} / \mathrm{CHAC}$.
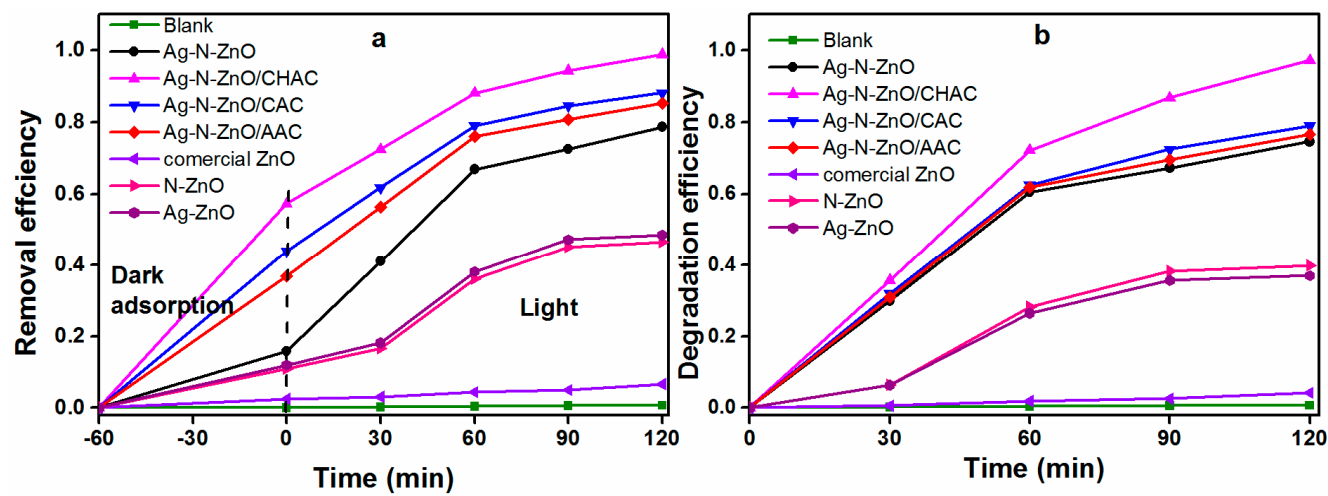

Figure 7. Cont. 


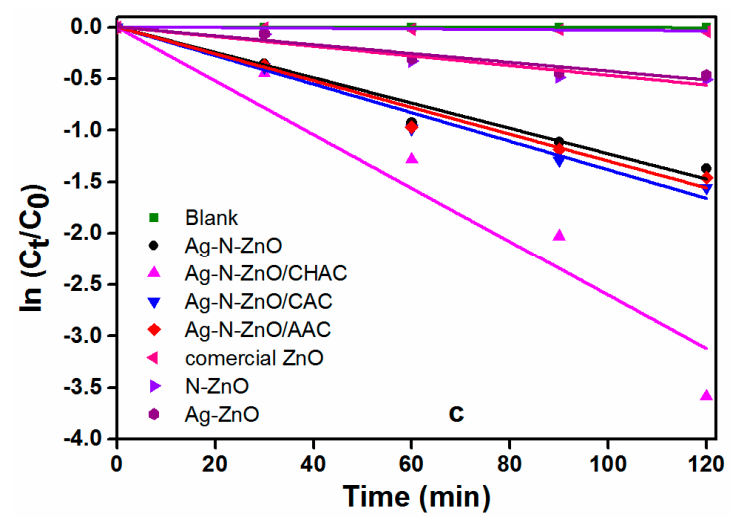

Figure 7. Photocatalytic degradation efficiency (a) $(30 \mathrm{mg} / \mathrm{L}$ initial concentration of MO solution), photocatalytic degradation efficiency of dark adsorption eliminated (b) (initial concentration of MO solution after dark adsorption experiment), and kinetic curves (c) of photocatalytic degradation of $\mathrm{MO}$ over different photocatalysts under visible light irradiation.

Furthermore, the photodegradation kinetics of $\mathrm{MO}$ on the four composite photocatalysts were investigated (Figure 7c). The kinetic curves of various photocatalysts follow First order kinetics and the degradation rate constants of all samples are presented in Table 3. The apparent rate constant of photocatalyst is in the following order: Ag-N-ZnO/ACs $>$ Ag-N-ZnO $>\mathrm{N}$, or Ag single-doped $\mathrm{ZnO}>$ commercial $\mathrm{ZnO}$, which indicated that $\mathrm{N}$, and $\mathrm{Ag}$ co-doped $\mathrm{ZnO}$ supported on $\mathrm{AC}$ can enhance the photacatalytic activity of the photocatalyst. Ag-N-ZnO/CHAC achieved excellent photocatalytic performance with a $k$ value of $0.0260 \mathrm{~min}^{-1}$, which was 2.11 times that of $\mathrm{Ag}-\mathrm{N}-\mathrm{ZnO}\left(k=0.0123 \mathrm{~min}^{-1}\right)$.

Table 3. First order kinetic constants and relative coefficients for photocatalytic degradation of MO over the samples.

\begin{tabular}{ccc}
\hline Samples & $\boldsymbol{k}\left(\mathbf{m i n}^{-1}\right)$ & $\boldsymbol{R}^{\mathbf{2}}$ \\
\hline Blank & $6.24 \pm 0.12 \times 10^{-5 \mathrm{a}}$ & 0.9945 \\
Commercial ZnO & $3.28 \pm 0.10 \times 10^{-4 \mathrm{a}}$ & 0.9834 \\
Ag-ZnO & $4.28 \pm 0.13 \times 10^{-3 \mathrm{~b}}$ & 0.9697 \\
$\mathrm{~N}-\mathrm{ZnO}$ & $4.69 \pm 0.08 \times 10^{-3 \mathrm{~b}}$ & 0.9698 \\
Ag-N-ZnO & $1.23 \pm 0.04 \times 10^{-2 \mathrm{c}}$ & 0.9854 \\
Ag-N-ZnO/CHAC & $2.60 \pm 0.05 \times 10^{-2 \mathrm{~d}}$ & 0.9661 \\
Ag-N-ZnO/CAC & $1.38 \pm 0.03 \times 10^{-2 \mathrm{c}}$ & 0.9912 \\
Ag-N-ZnO/AAC & $1.30 \pm 0.02 \times 10^{-2 \mathrm{c}}$ & 0.9874 \\
\hline
\end{tabular}

Different lowercase letters show significance between samples and $k$ at $p<0.05$ using least significant difference (LSD).

\subsection{Photogenerated Active Radical Species}

In order to detect the involvement of radical species generated in the photocatalytic process, the ESR spin-trap with DMPO technique has also been performed on illuminated photocatalysts [39]. The results are displayed in Figure 8. Dark treatment experiments show that no signals $\left(\cdot \mathrm{OH}\right.$ and $\cdot \mathrm{O}_{2}{ }^{-}$) were detected in the presence of photocatalysts. As shown in Figure 8a, under visible light irradiation, the signals of DMPO-.OH for all samples can be clearly observed, and the intensity increases with the addition of AC. This finding is further defined by the formation of $\cdot \mathrm{OH}$ during the process of photocatalytic degradation of dyes in the presence of photocatalysts and visible light irradiation. Moreover, the superoxide radical $\left(\cdot \mathrm{O}_{2}^{-}\right)$was observed, as displayed in Figure 8 b. When photocatalysts were irradiated with visible light, $\mathrm{Ag}-\mathrm{N}-\mathrm{ZnO} / \mathrm{CHAC}$ could generate stronger and more obvious peaks of the DMPO-. $\mathrm{O}_{2}{ }^{-}$species than other samples, indicating that $\mathrm{Ag}-\mathrm{N}-\mathrm{ZnO} / \mathrm{CHAC}$ can generate more $\cdot \mathrm{O}_{2}{ }^{-}$radicals. In particular, under identical operational conditions, the Ag- $\mathrm{N}-\mathrm{ZnO} / \mathrm{CHAC}$ composite photocatalyst exhibits the strongest intensities of $\cdot \mathrm{OH}$ and $\cdot \mathrm{O}_{2}{ }^{-}$, which seems consistent with the 
more efficient charge separation and transfer from $\mathrm{Ag}-\mathrm{N}-\mathrm{ZnO} / \mathrm{CHAC}$ as investigated by the above photoluminescence (PL) spectrum analysis. The smaller particle size of Ag-N-ZnO/CHAC could facilitate the rapid diffusion of photogenerated carriers to the semiconductor surface, resulting in a decrease of the recombination rate of the carrier. Therefore, more electrons and holes can react with $\mathrm{O}_{2}$ and $-\mathrm{OH}$ to form $\cdot \mathrm{OH}$ and $\cdot \mathrm{O}_{2}{ }^{-}$, respectively, resulting in stronger intensities of $\cdot \mathrm{OH}$ and $\cdot \mathrm{O}_{2}{ }^{-}$. This result is in strong agreement with photocatalytic activity.
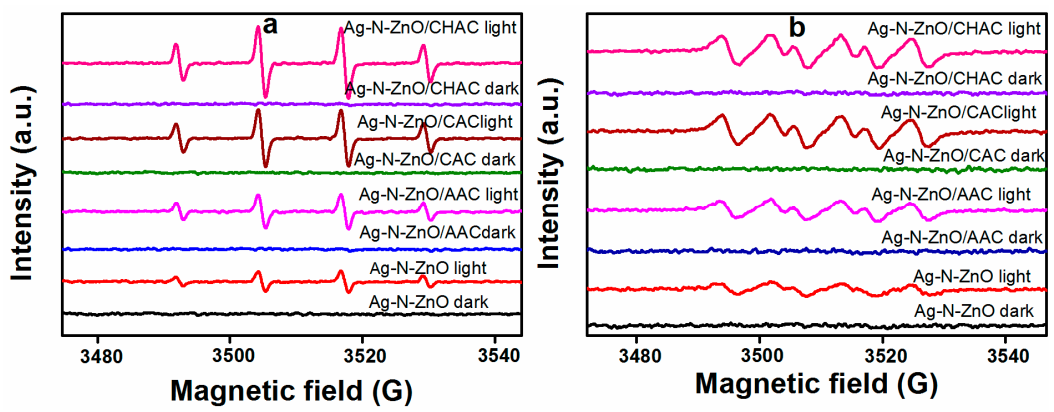

Figure 8. ESR spectra of radical adducts trapped by DMPO over the different photocatalyst dispersions under visible light irradiation; (a) DMPO--OH formed in irradiated aqueous dispersions; (b) $\mathrm{DMPO}-\mathrm{O}_{2} \cdot-$ formed in irradiated methanol dispersions.

\subsection{Mechanism of Photodegradation}

To further understand the underlying mechanism involved in the degradation of $\mathrm{MO}$ on the photocatalysts under visible light irradiation, we conducted radical, hole, and electron scavenging experiments to detect the major role of reactive species in the photocatalytic process. Tert-butanol $(\mathrm{t}-\mathrm{BuOH})$ was adopted to quench the hydroxyl radical $(\cdot \mathrm{OH})$ [24], p-benzoquinone (p-BQ) was used as the superoxide radical $\left(\cdot \mathrm{O}_{2}^{-}\right)$scavengers [10], ammonium oxalate $(\mathrm{AO})$ was introduced as the scavenger of holes $\left(\mathrm{h}^{+}\right)$[23], and the electrons $\left(\mathrm{e}^{-}\right)$were trapped by $\mathrm{K}_{2} \mathrm{~S}_{2} \mathrm{O}_{8}$ [39]. The degradation rate of $\mathrm{MO}$ over photocatalysts in the presence of the scavengers is presented in Figure 9. The addition of $\mathrm{t}-\mathrm{BuOH}$ and $\mathrm{p}-\mathrm{BQ}$ markedly decreased the removal rate of $\mathrm{MO}$. By contrast, the removal efficiency of $\mathrm{MO}$ only slightly changed in the photocatalytic process in the presence of $\mathrm{AO}$ and $\mathrm{K}_{2} \mathrm{~S}_{2} \mathrm{O}_{8}$. The removal rate of the $\mathrm{MO}$ over photocatalysts in the presence of scavengers followed the order: $\mathrm{p}-\mathrm{BQ}<\mathrm{t}-\mathrm{BuOH}<\mathrm{AO}<\mathrm{K}_{2} \mathrm{~S}_{2} \mathrm{O}_{8}$. Therefore, the reactive species $\cdot \mathrm{OH}$ and $\cdot \mathrm{O}_{2}{ }^{-}$play more important roles in the photocatalytic degradation process of $\mathrm{MO}$ over composite photocatalysts, which agrees with the common viewpoint on the photocatalytic degradation of azo dyes on photocatalysts [40,41].

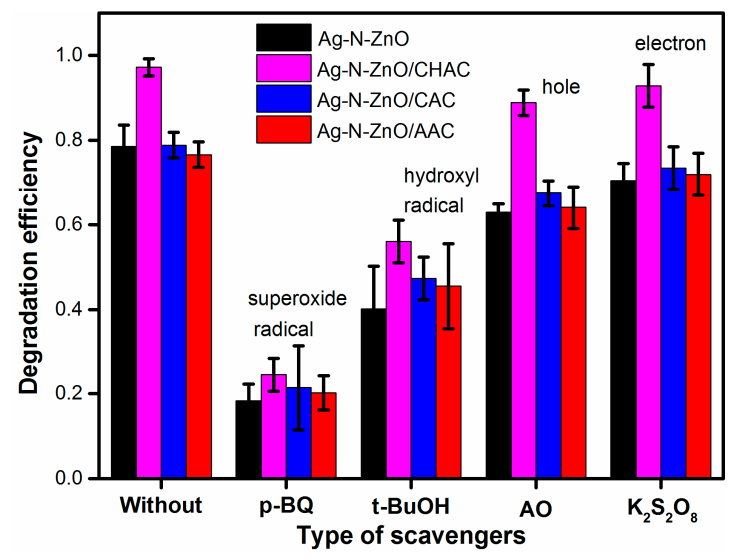

Figure 9. The removal rate of $\mathrm{MO}$ over $\mathrm{Ag}-\mathrm{N}-\mathrm{ZnO} / \mathrm{ACs}$ in the presence of various scavengers. 
The enhanced photocatalytic activity of the Ag-N-ZnO/AC composite photocatalyst can be understood as follows and the possible mechanisms are illustrated in Figure 10. As the photocatalyst is irradiated by visible light, $\mathrm{ZnO}$ is activated to produce the photogenerated electrons and holes. Then the photogenerated electrons and holes react with $\mathrm{O}_{2}$ and $-\mathrm{OH}$, respectively, to form $\cdot \mathrm{OH}$ and $\cdot \mathrm{O}_{2}{ }^{-}$. The $\mathrm{MO}$ is then decomposed by $\cdot \mathrm{OH}$ and $\cdot \mathrm{O}_{2}{ }^{-}$. The high photocatalytic activity of the Ag-N-ZnO/AC photocatalysts under visible light may be attributed to $\mathrm{N}$ and Ag dopants as well as to the AC. Firstly, this phenomenon is achieved by substituting $\mathrm{O}$ sites with $\mathrm{N}$, which can form impure energy levels. Thus, electrons transfer from the valence band (VB) to the N $2 p$ and from the $\mathrm{N} 2 \mathrm{p}$ to the conduction band (CB), inducing a longer wavelength of the absorbed photon [13]. Secondly, the photogenerated electrons excited by visible light were trapped by Ag after they were transferred to the conduction band of the prepared composites, which prevented their recombination with holes [35]. Thirdly, AC acts as a barrier to the inhibitive action of ZnO crystal growth, which increased the surface of contact between $\mathrm{MO}$ and the photocatalyst. AC could absorb a large part of irradiation, which traded off its advantage as an adsorptive support to concentrate MO molecules. Some hot-spots could be formed on the surface of the AC particles, and the MO molecules around the "hot spots" could be decomposed in the presence of $\mathrm{O}_{2}$ dissolved in water [24]. These factors all resulted in the high photocatalytic activity of the Ag-N-ZnO/AC composite photocatalyst.

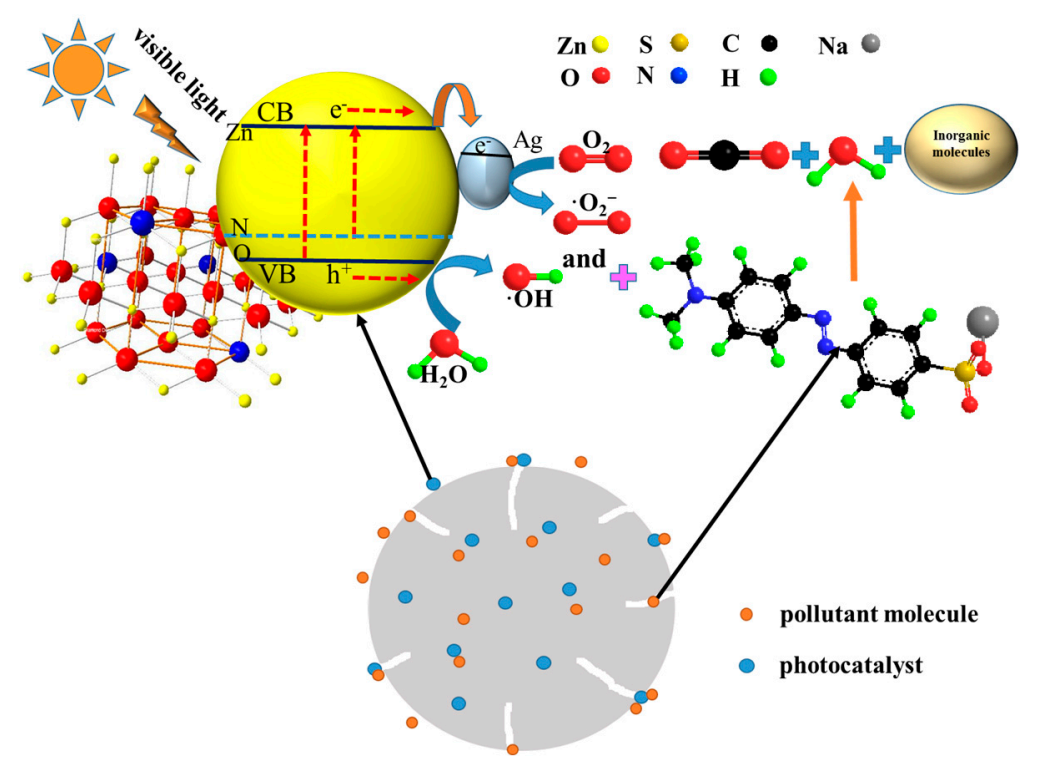

Figure 10. Mechanism for photocatalytic degradationaction of $\mathrm{MO}$ on the $\mathrm{Ag}-\mathrm{N}-\mathrm{ZnO} / \mathrm{AC}$ photocatalyst.

\subsection{Stability of Composite Photocatalyst}

In addition to photocatalytic properties, the stability and recyclability of the photocatalyst are important for its potential application. To evaluate the stability of the photocatalyst, the photocatalytic degradation of recycled photocatalysts was carried out under visible light irradiation. The photocatalyst was collected after the photocatalytic reaction, then washed with distilled water and ethanol and dried in an oven at $80^{\circ} \mathrm{C}$ before reuse. As shown in Figure 11, theAg-N-ZnO/CHACphotocatalyst retained its high photocatalytic activity, and still the degradation efficiency of $\mathrm{MO}$ reached $94.32 \%$ after five recycle runs. The photocatalytic activity of $\mathrm{Ag}-\mathrm{N}-\mathrm{ZnO} / \mathrm{CHAC}$ only minimally decreased, which could be due to three reasons: (1) The pore of the composite photocatalyst were blocked resulting in the decrease of the ability of photocatalyst to concentrate MO molecules; (2) The photocatalyst was lost during the cycle processes; and (3) The partial active sites were deactivated or blocked due to not complete degradation of $\mathrm{MO}$ and $\mathrm{MO}$ intermediates during each previous cycle. The degradation efficiency of $\mathrm{MO}$ over $\mathrm{Ag}-\mathrm{N}-\mathrm{ZnO}$ decreased from $74.6 \%$ to $65.88 \%$ after five recycle runs. This phenomenon is 
mainly attributed to a higher loss of $\mathrm{Ag}-\mathrm{N}-\mathrm{ZnO}$ photocatalysts during the difficult separation processes. These results indicate that AC as supported materials can not only improve photocatalytic activity, but also improve the stability of the photocatalyst.

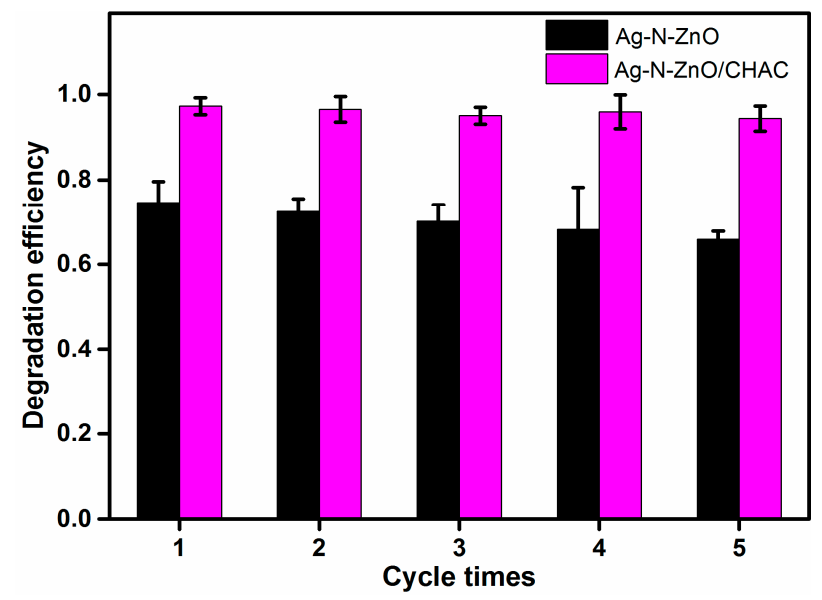

Figure 11. Recycled photoactivity testing of Ag-N-ZnO and Ag-N-ZnO/CHAC photocatalysts under visible light irradiation.

\subsection{Correlation Analysis}

It is important to study the correlation between the physical and chemical properties of the photocatalyst and its degradation properties. Figure 12 shows that the $\mathrm{S}_{\mathrm{BET}}$ of Ag-N-ZnO/ACs presented a good positive correlation with $\mathrm{MO}$ removal rate $\left(R^{2}=0.9994\right)$. A large specific surface area of the photocatalyst will result in a high removal rate of $\mathrm{MO}$. This result is consistent with those obtained above. Therefore, the best photocatalytic degradation of $\mathrm{MO}$ was observed over Ag-N-ZnO/CHAC.

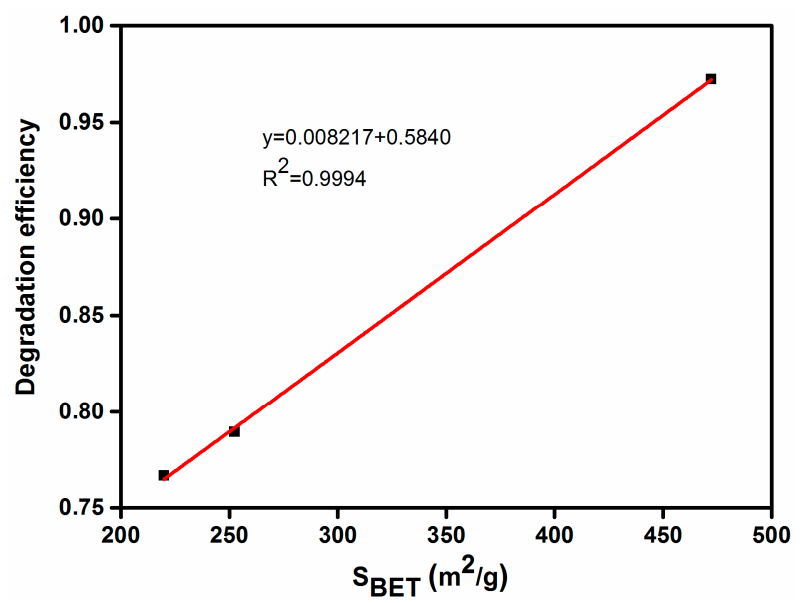

Figure 12. Correlation curve between BET surface area of Ag-N-ZnO/CHAC, Ag-N-ZnO/CAC and Ag-N-ZnO/AAC and remove efficiency of MO.

\section{Conclusions}

All composite photocatalysts were successfully prepared through sol-gel and ultrasonic method. $\mathrm{Ag}-\mathrm{N}-\mathrm{ZnO} / \mathrm{ACs}$ exhibited higher photocatalytic activity for $\mathrm{MO}$ than for the unsupported Ag-N-ZnO. Among all Ag-N-ZnO/ACs, Ag-N-ZnO/CHAC exhibited the highest photocatalytic activity for MO. The highest surface area and the strongest adsorption performance of CHAC resulted in inhibiting 
the growth of $\mathrm{ZnO}$ crystallite. The smaller particle size of Ag-N-ZnO/CHAC could facilitate the rapid diffusion of photogenerated carriers to the semiconductor surface, resulting in decreasing the recombination rate of the carrier. In addition, the highest photocatalytic activity of Ag- $\mathrm{N}-\mathrm{ZnO} / \mathrm{CHAC}$ is due to the fact that $\mathrm{Ag}-\mathrm{N}-\mathrm{ZnO} / \mathrm{CHAC}$ has an abundant pore structure and $\mathrm{CHAC}$ absorbs at slightly higher wavelengths than that of $\mathrm{ZnO}$. The adsorption of $\mathrm{MO}$ over photocatalyst reached equilibrium in about $60 \mathrm{~min}$ and fitted the pseudo-second-order kinetics. The degradation of $\mathrm{MO}$ on photocatalyst followed first order kinetics. Reactive species $\cdot \mathrm{OH}$ and $\cdot \mathrm{O}_{2}{ }^{-}$played more important roles in the photocatalytic degradation process of $\mathrm{MO}$ over the composite photocatalysts. The Ag- $\mathrm{N}-\mathrm{ZnO} / \mathrm{CHAC}$ photocatalyst retained higher photocatalytic activity than the unsupported $\mathrm{Ag}-\mathrm{N}-\mathrm{ZnO}$ after five recycle runs. Hence, the Ag-N-ZnO/CHAC photocatalyst could be considered a promising material for application in the removal of $\mathrm{MO}$ from aqueous solution.

Acknowledgments: This work was supported financially by funding from the International Scientific and Technological Cooperation Project of Xinjiang Bingtuan (2013BC002), International Science and Technology Cooperation Program of Shihezi University (GJHZ201601) and Scientific Research Foundation for Changjiang Scholars of Shihezi University (CJXZ201501).

Author Contributions: Zhansheng $\mathrm{Wu}$ and Xiaoqing Chen provided the idea and drafted the manuscript. Bang-Ce Ye approved the article research mentality. Xiaoqing Chen and Zhenzhen Gao designed and carried out the experiment. Zhansheng $\mathrm{Wu}, \mathrm{Xiaoqing} \mathrm{Chen}$ and Bang-Ce Ye improved data analysis and data interpretation of manuscript.

Conflicts of Interest: The authors declare no conflict of interest.

\section{References}

1. Jo, W.K.; Selvam, N.C.S. Enhanced visible light-driven photocatalytic performance of $\mathrm{ZnO}-\mathrm{g}-\mathrm{C}_{3} \mathrm{~N}_{4}$ coupled with grapheme oxide as a novel ternary nanocomposite. J. Hazard. Mater. 2015, 299, 462-470. [CrossRef] [PubMed]

2. Kumar, R.; Kumar, G. ZnO nano-mushrooms for photocatalytic degradation of methyl orange. Mater. Lett. 2013, 97, 100-103. [CrossRef]

3. Chamjangali, M.A.; Bagherian, G.; Bahramian, B.; Rad, B.F. Synthesis and application of multiple rods gold-zinc oxide nanostructures in the photocatalytic degradation of methyl orange. Int. J. Environ. Sci. Technol. 2015, 12, 151-160. [CrossRef]

4. Zhu, H.Y.; Jiang, R.; Fu, Y.Q.; Guan, Y.J.; Yao, J.; Xiao, L.; Zeng, G.M. Effective photocatalytic decolorization of methyl orange utilizing $\mathrm{TiO}_{2} / \mathrm{ZnO} /$ chitosan nanocomposite films under simulated solar irradiation. Desalination 2012, 286, 41-48. [CrossRef]

5. Tripathy, N.; Ahmad, R.; Song, J.E.; Ko, H.A.; Hahn, Y.B.; Khang, G. Photocatalytic degradation of methyl orange dye by ZnO nanoneedle under UV irradiation. Mater. Lett. 2014, 136, 171-174. [CrossRef]

6. Tian, F.; Wu, Z.S.; Chen, Q.Y.; Yan, Y.J.; Cravotto, G.; Wu, Z.L. Microwave-induced crystallization of $\mathrm{AC} / \mathrm{TiO}_{2}$ for improving the performance of rhodamine B dye degradation. Appl. Surf. Sci. 2015, 351, 104-112. [CrossRef]

7. Prasad, G.K.; Ramacharyulu, P.; Singh, B.; Batra, K.; Srivastava, A.R.; Ganesan, K.; Vijayaraghavan, R. Sun light assisted photocatalytic decontamination of sulfur mustard using $\mathrm{ZnO}$ nanoparticles. J. Mol. Catal. A Chem. 2011, 349, 55-62. [CrossRef]

8. Samadi, M.; Shivaee, H.A.; Zanetti, M.; Pourjavadi, A.; Moshfegh, A. Visible light photocatalytic activity of novel MWCNT-doped ZnO electrospun nanofibers. J. Mol. Catal. A Chem. 2012, 359, 42-48. [CrossRef]

9. Xiong, Q.; Zhou, M.; Qian, X. The preparation and visible light photocatalytic activity of $\mathrm{ZnO}^{-} \mathrm{TiO}_{2}$ nanofibers. Adv. Mater. Res. 2012, 472, 3441-3444. [CrossRef]

10. Wang, X.J.; Song, J.K.; Huang, J.Y.; Zhang, J.; Wang, X.; Ma, R.R.; Wang, J.Y.; Zhao, J.F. Activated carbon-based magnetic $\mathrm{TiO}_{2}$ photocatalyst co-doped with iodine and nitrogen for organic pollution degradation. Appl. Surf. Sci. 2016, 390, 190-201. [CrossRef]

11. Le, S.K.; Jiang, T.S.; Li, Y.W.; Zhao, Q.; Li, Y.Y.; Fang, W.B.; Gong, M. Highly efficient visible-light-driven mesoporous graphitic carbon nitride/ZnO nanocomposite photocatalysts. Appl. Catal. B Environ. 2017, 200, 601-610. [CrossRef] 
12. Jaramillo-Páez, C.; Navío, J.A.; Hidalgo, M.C.; Macías, M. High UV-photocatalytic activity of ZnO and $\mathrm{Ag} / \mathrm{ZnO}$ synthesized by a facile method. Catal. Today 2017, 284, 121-128. [CrossRef]

13. Liu, D.D.; Wu, Z.S.; Tian, F.; Ye, B.C.; Tong, Y.B. Synthesis of $\mathrm{N}$ and La co-doped $\mathrm{TiO}_{2} / \mathrm{AC}_{\text {photocatalyst by }}$ microwave irradiation for the photocatalytic degradation of naphthalene. J. Alloys Compd. 2016, 676, 489-498. [CrossRef]

14. Thi, V.H.T.; Lee, B.K. Great improvement on tetracycline removal using ZnO rod-activated carbon fiber composite prepared with a facile microwave method. J. Hazard. Mater. 2017, 324, 329-339. [CrossRef]

15. Bhirud, A.; Sathaye, S.; Waichal, R.; Park, C.J.; Kale, B. In situ preparation of N-ZnO/grapheme nanocomposites: Excellent candidate as a photocatalyst for enhanced solar hydrogen generation and high performance supercapacitor electrode. J. Mater. Chem. A 2015, 3, 17050-17063. [CrossRef]

16. Jang, Y.J.; Jang, Y.H.; Kim, D.H. Nanostructuredcarbon- $\mathrm{TiO}_{2}$ shells onto silica beads as a promising candidate for the alternative photoanode in dye-sensitized solar cells. Sci. Adv. Mater. 2015, 7, 956-963. [CrossRef]

17. Vaiano, V.; Sacco, O.; Sannino, D.; Ciambelli, P. Nanostructured N-doped $\mathrm{TiO}_{2}$ coated on glass spheres for the photocatalytic removal of organic dyes under UV or visible light irradiation. Appl. Catal. B Environ. 2015, 170, 153-161. [CrossRef]

18. Wang, J.J.; Jing, Y.H.; Ouyang, T.; Chang, C.T. Preparation of 13X from waste quartz and photocatalytic reaction of methyl orange on $\mathrm{TiO}_{2}$ /ZSM-5, 13X and Y-zeolite. J. Nanosci. Nanotechnol. 2015, 15, 6141-6149. [CrossRef] [PubMed]

19. Ragupathy, S.; Raghu, K.; Prabu, P. Synthesis and characterization of $\mathrm{TiO}_{2}$ loaded cashew nut shell activated carbon and photocatalytic activity on BG and MB dyes under sunlight radiation. Spectrochim. Acta A 2015, 138, 314-320. [CrossRef] [PubMed]

20. Gar Alalm, M.; Tawfik, A.; Ookawara, S. Solar photocatalytic degradation of phenol by $\mathrm{TiO}_{2} / \mathrm{AC}_{\text {prepared }}$ by temperature impregnation method. Desalination Water Treat. 2014, 57, 835-844. [CrossRef]

21. Rimoldi, L.; Ambrosi, C.; Di Liberto, G.; Lo Presti, L.; Ceotto, M.; Oliva, C.; Ardizzone, S. Impregnation versus bulk synthesis: How the synthetic route affects the photocatalytic efficiency of $\mathrm{Nb} / \mathrm{Ta}$ : $\mathrm{N}$ codoped $\mathrm{TiO}_{2}$ nanomaterials. J. Phys. Chem. C 2015, 119, 24104-24115. [CrossRef]

22. Chandraboss, V.L.; Kamalakkannan, J.; Prabha, S.; Senthilvelan, S. An efficient removal of methyl violet from aqueous solution by an AC-Bi/ZnO nanocomposite material. RSC Adv. 2015, 5, 25857-25869. [CrossRef]

23. Chen, X.Q.; Wu, Z.S.; Liu, D.D.; Gao, Z.Z. Preparation of $\mathrm{ZnO}$ photocatalyst for the efficient and rapid photocatalytic degradation of azo dyes. Nanoscale Res. Lett. 2017, 12, 143. [CrossRef] [PubMed]

24. Liu, D.D.; Liu, Y.M.; Wu, Z.S.; Tian, F.; Ye, B.C.; Chen, X.Q. Enhancement of photodegradation of $\mathrm{Ce}, \mathrm{N}$, and $\mathrm{P}$ tri-doped $\mathrm{TiO}_{2} / \mathrm{AC}$ by microwave radiation with visible light response for naphthalene. J. Taiwan Inst. Chem. E 2016, 68, 506-513. [CrossRef]

25. Pastrana-Martínez, L.M.; Morales-Torres, S.; Papageorgiou, S.K.; Katsaros, F.K.; Romanos, G.E.; Figueiredo, J.L.; Faria, J.L.; Falaras, P.; Silva, A.M. Photocatalytic behaviour of nanocarbon-TiO 2 composites and immobilization into hollow fibres. Appl. Catal. B Environ. 2013, 142, 101-111. [CrossRef]

26. Khan, G.; Kim, Y.K.; Choi, S.K.; Han, D.S.; Abdel-Wahab, A.; Park, H. Evaluating the catalytic effects of carbon materials on the photocatalytic reduction and oxidation reactions of $\mathrm{TiO}_{2}$. Bull. Korean Chem. Soc. 2013, 34, 1137-1144. [CrossRef]

27. Karunakaran, C.; Rajeswari, V.; Gomathisankar, P. Antibacterial and photocatalytic activities of sonochemically prepared $\mathrm{ZnO}$ and Ag-ZnO. J. Alloys Compd. 2010, 508, 587-591. [CrossRef]

28. Xie, J.; $\mathrm{Wu}, \mathrm{Q}$. One-pot synthesis of $\mathrm{ZnO} / \mathrm{Ag}$ nanospheres with enhanced photocatalytic activity. Mater. Lett. 2010, 64, 389-392. [CrossRef]

29. Alammar, T.; Mudring, A.V. Facile preparation of Ag/ZnO nanoparticles via photoreduction. J. Mater. Sci. 2009, 44, 3218-3222. [CrossRef]

30. Muthulingam, S.; Lee, I.H.; Uthirakumar, P. Highly efficient degradation of dyes by carbon quantum dots/N-doped zinc oxide (CQD/N-ZnO) photocatalyst and its compatibility on three different commercial dyes under daylight. J. Colloid Interface Sci. 2015, 455, 101-109. [CrossRef] [PubMed]

31. Ansari, S.A.; Khan, M.M.; Ansari, M.O.; Lee, J.; Cho, M.H. Biogenic synthesis, photocatalytic, and photoelectrochemical performance of Ag-ZnO nanocomposite. J. Phys. Chem. C 2013, 117, 27023-27030. [CrossRef] 
32. Zhang, X.Y.; Deng, Y.J.; Liu, J.K.; Lu, Y.; Yang, X.H. Mass preparation and novel visible light photocatalytic activity of C and Ag Co-modified ZnO nanocrystals. J. Colloid Interface Sci. 2015, 459, 1-9. [CrossRef] [PubMed]

33. Li, W.J.; Kong, C.Y.; Qin, G.P.; Ruan, H.B.; Fang, L. p-Type conductivity and stability of Ag-N codoped ZnO thin films. J. Alloys Compd. 2014, 609, 173-177. [CrossRef]

34. Yu, Z.B.; Yin, L.C.; Xie, Y.P.; Liu, G.; Ma, X.L.; Cheng, H.M. Crystallinity-dependent substitutional nitrogen doping in $\mathrm{ZnO}$ and its improved visible light photocatalytic activity. J. Colloid Interface Sci. 2013, 400, 18-23. [CrossRef] [PubMed]

35. Hou, J.; Huang, L.; Yang, Z.M.; Zhao, Y.Q.; Deng, C.R.; Chen, Y.C.; Li, X. Adsorption of ammonium on biochar prepared from giant reed. Environ. Sci. Pollut. Res. 2016, 23, 19107-19115. [CrossRef] [PubMed]

36. Ge, X.Y.; Wu, Z.S.; Wu, Z.L.; Yan, Y.J.; Cravotto, G.; Ye, B.C. Microwave-assisted modification of activated carbon with ammonia for efficient pyrene adsorption. J. Ind. Eng. Chem. 2016, 39, 27-36. [CrossRef]

37. Kuriakose, S.; Choudhary, V.; Satpati, B.; Mohapatra, S. Facile synthesis of Ag-ZnO hybrid nanospindles for highly efficient photocatalytic degradation of methyl orange. Phys. Chem. Chem. Phys. 2014, 16, 17560-17568. [CrossRef] [PubMed]

38. Zhang, J.; Wang, X.J.; Xia, P.; Wang, X.; Huang, J.Y.; Chen, J.; Louangsouphom, B.; Zhao, J.F. Enhanced sunlight photocatalytic activity and recycled Ag-N co-doped $\mathrm{TiO}_{2}$ supported by expanded graphite $\mathrm{C} / \mathrm{C}$ composites for degradation of organic pollutants. Res. Chem. Intermed. 2016, 42, 5541-5557. [CrossRef]

39. Zhang, Y.H.; Chen, Z.; Liu, S.Q.; Xu, Y.J. Size effect induced activity enhancement and anti-photocorrosion of reduced graphene oxide/ $\mathrm{ZnO}$ composites for degradation of organic dyes and reduction of $\mathrm{Cr}(\mathrm{VI})$ in water. Appl. Catal. B Environ. 2013, 140, 598-607. [CrossRef]

40. Huang, N.; Shu, J.X.; Wang, Z.H.; Chen, M.; Ren, C.G.; Zhang, W. One-step pyrolytic synthesis of ZnO nanorods with enhanced photocatalytic activity and high photostability under visible light and UV light irradiation. J. Alloys Compd. 2015, 648, 919-929. [CrossRef]

41. Rimoldi, L.; Meroni, D.; Cappelletti, G.; Ardizzone, S. Green and low cost tetracycline degradation processes by nanometric and immobilized $\mathrm{TiO}_{2}$ systems. Catal. Today 2017, 281, 38-44. [CrossRef]

(C) 2017 by the authors. Licensee MDPI, Basel, Switzerland. This article is an open access article distributed under the terms and conditions of the Creative Commons Attribution (CC BY) license (http:/ / creativecommons.org/licenses/by/4.0/). 